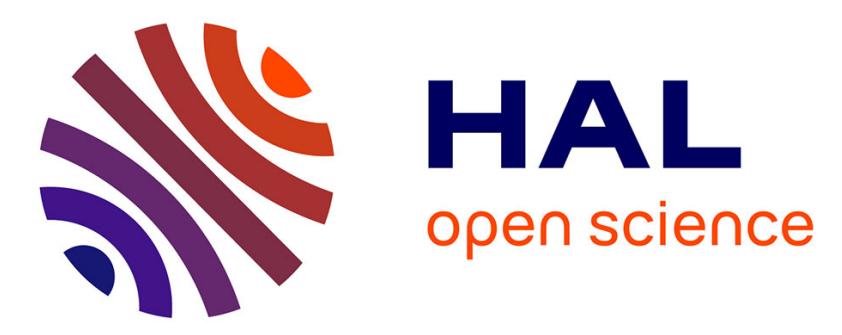

\title{
Observing Learner Engagement on Mind Mapping Activities Using Learning Analytics
}

\author{
Rubiela Carrillo, Yannick Prié, Elise Lavoué
}

\section{To cite this version:}

Rubiela Carrillo, Yannick Prié, Elise Lavoué. Observing Learner Engagement on Mind Mapping Activities Using Learning Analytics. 14th European Conference on Technology Enhanced Learning (EC-TEL 2019), Sep 2019, Delft, Netherlands. pp.668-672, 10.1007/978-3-030-29736-7_63 . hal02314973

\section{HAL Id: hal-02314973 \\ https://hal.science/hal-02314973}

Submitted on 17 Oct 2019

HAL is a multi-disciplinary open access archive for the deposit and dissemination of scientific research documents, whether they are published or not. The documents may come from teaching and research institutions in France or abroad, or from public or private research centers.
L'archive ouverte pluridisciplinaire HAL, est destinée au dépôt et à la diffusion de documents scientifiques de niveau recherche, publiés ou non, émanant des établissements d'enseignement et de recherche français ou étrangers, des laboratoires publics ou privés. 


\title{
Observing learner engagement on mind mapping activities using Learning Analytics
}

\author{
Rubiela Carrillo ${ }^{1}$, Yannick Prié ${ }^{2}$, and Élise Lavoué ${ }^{3}$ \\ 1 Université de Lyon, Université Lyon 1, LIRIS, CNRS5205, France \\ rubiela.carrillo-rozo@liris.cnrs.fr \\ 2 Université de Nantes, LS2N - UMR 6004, CNRS, France \\ yannick.prie@univ-nantes.fr \\ 3 University of Lyon, University Jean Moulin Lyon 3, iaelyon school of Management, \\ CNRS, LIRIS, France elise.lavoue@univ-lyon3.fr
}

\begin{abstract}
Research on learner engagement has increased in recent years arguing that it favors academic success. Teachers want their learners to engage in meaningful learning activities, like mind mapping, but they lack clues for observing their engagement along the activity. In this paper, we propose indicators of behavioural and cognitive dimensions of learner engagement for mind mapping activities based on interaction traces. Our indicators have been defined from final mind maps as well as from the mind mapping processes. We discuss implications for the observation of learner engagement in learning activities similar to mind mapping.
\end{abstract}

Keywords: Engagement · Indicators · Mind map · Learning Analytics

\section{Introduction}

Mind maps are graphic representations composed of nodes and links, in which the nodes represent ideas and the links represent their connections. Their first educational uses were mainly to support instruction and reading, while latest uses support the mapping processes inspired by constructivist theories [6] and the active learning benefits. Researchers in educational psychology have defined several dimensions of learner engagement (e.g. behavioural, cognitive) [2] to facilitate its observation. Behavioural engagement refers to observable actions to carry out a learning task. Cognitive engagement relates to strategies for accomplishing a learning task. We consider that learners' actions to elaborate mind maps may describe their behaviour, and that mapping activity may expose their cognitive processes and strategies.

Indicators could highlight learner engagement in mind mapping activities and help teachers to adapt their pedagogical strategies. However, existing indicators mainly target the assessment of the final mind maps [1], and those that are obtained from the mapping processes lack representations of such processes [8]. [4] propose indicators from learners' traces and represent mind mapping processes but only for strictly hierarchical graphs. We think that mind mapping activities should allow learners to express freely their ideas, without imposing structures. 
In this paper, we propose behavioural and cognitive indicators of learner engagement to assist teachers in monitoring and assessing mind mapping activities. Methods from Learning Analytics can be used to collect and analyse learners' interaction traces during mind mapping in order to obtain such indicators.

\section{Theoretical model and data sources to define indicators}

We propose a model of behavioural and cognitive engagement with four characteristics (i.e. participation, effort, meta-cognitive and cognitive strategies) that could be observed along mind mapping activities. Participation [5] is associated with the behavioural dimension. Effort is present in both dimensions, as behavioural effort (i.e. quantity) and cognitive effort (i.e. quality) [3]. Metacognitive and cognitive strategies [7] are related to the cognitive dimension of engagement. We associate each of these characteristics with indicators obtained from the final mind maps and the sequences of actions carried out to construct them. Final maps refer to their elements (i.e. nodes and links), and to their properties (e.g. title, description, URL, position X, position Y). Sequences of actions are defined by the creation, deletion, modification and displacement actions, applied to the mind map elements. Each action is associated with its time stamp, which allows to reconstruct the activity.

\section{Behavioural and cognitive engagement indicators}

\subsection{Indicators of participation}

- Number of elements: different trends can be found according to the type of elements created: definition of ideas (a greater number of nodes than links), or association of ideas (a greater number of links than nodes).

- Duration of the construction: period of time between the first and the last action to build the mind map.

- Time between two consecutive actions: a learner who interrupts his/her actions for a significant amount of time (determined by the teacher) may be in difficulty or poorly engaged behaviourally.

\subsection{Indicators of behavioural effort}

- Ratio between the number of elements and the minimum expected number: a mind map with a very poor proportion of expected elements may suggest a difficulty not overcome because of lack of knowledge or effort.

- Number of elements with expected minimum properties: when learners do not define the properties of an element, considered crucial for interpreting the final map, they may have difficulties and lack effort.

- Number of consecutive sequences of creation-deletion of a element: the creation of the last element that is not removed may be interpreted as a possible solution to a difficulty, and to show the learner's effort. 
- Number of displacements on the set of nodes: too high values may indicate difficulties with the subject of the map, or possible problems with the mapping tool interface.

- Number of displacements of each node on the mind map: may identify concepts that require more structuring effort.

- Number of modifications on the set of elements: may provide clues on the difficulties in defining the elements and the efforts made to solve them; or a lack of control over the mapping tool.

- Number of modifications in the properties of each element: a very high value of the number of title modifications may indicate the difficulty in defining it.

\subsection{Indicators of cognitive effort}

- Pertinence of the element properties: inadequate values of the properties may be the result of a weak cognitive engagement to overcome a difficulty.

- Pertinence of a created (and not deleted) element following consecutive sequences of creation-deletion: the last created element may be evaluated to judge if it brings quality to the map. It may reflect the learner's cognitive effort in face of a difficulty.

- Pertinence of displacements of the same node: when the learner move repeatedly a node to a place that does not add meaning to the close and connected elements, the idea represented by the node may require more cognitive effort from the learner to be articulated.

- Pertinence of modifications made to the set of elements: modifications improving the mind map quality may reflect cognitive effort.

- Pertinence of modifications to the properties of a element: modifications not considered relevant may reflect a low cognitive effort of the learner.

\subsection{Indicators of meta-cognitive strategies}

- Construction approach: may be 1) based on a logical order (creating links between two nodes when these nodes are created, or creating links at the end once all the nodes have been created), or 2) based on a strong trial and error. A trial and error approach does not show the follow-up of a meta-cognitive planning strategy because of difficulties to understand the subject and to use the mapping tool, or because of a low cognitive engagement in the activity.

- Pertinence of the actions on the elements following a help request: learners self-regulate when they monitor their own activity, identify their needs, seek for help, and adapt their map according to the answers.

- Pertinence of the actions on the elements following a search for information: learners self-regulate when they identify their information needs to build the map, search the information in a tool, and adapt their map according to the results obtained. 


\subsection{Indicators of cognitive strategies}

- Ratio between the number of titled elements and the total number of elements: calculated from the final mind map, it focuses on the elaboration strategies used.

- Length of the node titles: length of the node titles in the final map.

- Pertinence of the links: refers to the pertinence of the links between the nodes in the final map, and to the pertinence of the titles of these links.

- Pertinence of the topological structure: pertinence of the spatial distribution of the nodes in the final graph.

- Pertinence of all actions on the elements over time: can be evaluated from the sequences of actions identified over time.

\section{Discussion and future works}

The next step will be to implement and evaluate our indicators on a dashboard. The visualization of indicators over time on a dashboard could favor the monitoring of learner engagement during mind mapping processes. Our main concern is to evaluate the relevance of the proposed indicators for teachers. Our future works will be directed toward the evaluation of our model of engagement for monitoring other learning activities that rely on the construction of resources such as text writing. We may consider the paragraphs as nodes, and the ideas that articulate them as links.

\section{References}

1. Cañas, A.J., Bunch, L., Novak, J.D., Reiska, P.: Cmapanalysis: an extensible concept map analysis tool. Journal for Educators, Teachers and Trainers (2013)

2. Fredricks, J.A., Blumenfeld, P.C., Paris, A.H.: School Engagement: Potential of the Concept, State of the Evidence. Review of Educational Research 74(1), 59-109 (Mar 2004)

3. Fredricks, J.A., McColskey, W.: The Measurement of Student Engagement: A Comparative Analysis of Various Methods and Student Self-report Instruments. In: Christenson, S.L., Reschly, A.L., Wylie, C. (eds.) Handbook of Research on Student Engagement, pp. 763-782. Springer US (2012)

4. Miller, N.L., Cañas, A.J., Novak, J.D.: Use of the Cmaptools Recorder to explore acquisition of skill in concept mapping. p. 8. Tallinn, Estonia \& Helsinki, Finland (2008)

5. Newmann, F.M.: Student Engagement and Achievement in American Secondary Schools. Teachers College Press, 1234 Amsterdam Avenue, New York, NY 10027 (1992)

6. Novak, J.D.: Learning, Creating, and Using Knowledge: Concept maps as facilitative tools in schools and corporations. Journal of e-Learning and Knowledge Society 6(3) (Sep 2010)

7. Pintrich, P.R.: The role of motivation in promoting and sustaining self-regulated learning. International Journal of Educational Research 31(6), 459-470 (1999)

8. Yin, Y., Vanides, J., Ruiz-Primo, M.A., Ayala, C.C., Shavelson, R.J.: Comparison of two concept-mapping techniques: Implications for scoring, interpretation, and use. Journal of Research in Science Teaching 42(2), 166-184 (2005) 